\title{
Perception of Student Nurses on Variables Influencing Academic Achievement in Nnamdi Azikiwe University, Anambra State Nigeria
}

\author{
Nwambo Joshua Chidiebere ${ }^{1, ~ *}$, Ilo Clementine I. $^{2}$, Agbapuonwu Noreen E. ${ }^{2}$, \\ Nwankwo Ukamaka $\mathrm{C}^{2}{ }^{2}$ \\ ${ }^{1}$ AUN Clinic, American University of Nigeria, Yola, Nigeria \\ ${ }^{2}$ Department of Nursing Science, Nnamdi Azikiwe University, Nnewi Campus, Nigeria \\ Email address: \\ nwamboj@gmail.com (N. J. Chidiebere) \\ ${ }^{*}$ Corresponding author
}

\section{To cite this article:}

Nwambo Joshua Chidiebere, Ilo Clementine I., Agbapuonwu Noreen E., Nwankwo Ukamaka C. Perception of Student Nurses on Variables Influencing Academic Achievement in Nnamdi Azikiwe University, Anambra State Nigeria. American Journal of Nursing Science. Vol. 5, No. 6, 2016, pp. 258-265. doi: 10.11648/j.ajns.20160506.14

Received: September 23, 2016; Accepted: October 12, 2016; Published: November 17, 2016

\begin{abstract}
The training and academic performance of student nurses is the crux to having competent polyvalent nurses in the healthcare delivery system. This study sought to determine the perception of student nurses on the variables influencing academic achievement in Nnamdi Azikiwe University Nnewi Campus. A descriptive survey was used to elicit information from a sample of 108 respondents statistically drawn using stratified random sampling technique from a population of 146. Results indicated an overall poor academic performance. The significant variables that influence academic achievement as identified by the respondents were marital status, age, income, occupation and educational status of parents. Others include school location, basic amenities, stress, academic motivation, past academic records and study skills; learning approach, time management, group discussion and clinical experiences. The hypothesis revealed that there is a significant relationship between socioeconomic status of parents and the academic achievement of nursing students. Based on the findings, the researchers recommended that students, parents, teachers, administrators, policymakers and the government should make efforts to understand and examine these factors so as to initiate or make the necessary restructuring and interventions needed to revamp the academic performance of the students.
\end{abstract}

Keywords: Academic Performance, Student Nurses, Factors, Variables

\section{Introduction}

\subsection{Background of the Study}

The demand for qualified nurses in the health care system has led to several significant governments enquiries into issues associated with the recruitment and retention of nurses. These enquiries sought to understand the relationship between educational processes and preparation of student nurses for their eventual role in the nursing workforce $[1,2,3]$.

Nursing education is an exciting and challenging adventure that demands much from nursing students, in terms of time and energy. Nursing students encounter complex situations and conflicts which constitute factors that affect their academic performance which cannot be resolved only through theoretical knowledge and skills [4].

Over the years, discrepancies in the performance of nursing students have been observed, although students may be of comparable abilities, learn in the same environment and follow the same syllabus, their academic performance still vary. Bright students who fail to excel due to other factors, miss the opportunity to advance in education and to get employment [5]. Therefore, it is important to analyze variables of academic achievement due to its significant influence on learning at school.

Studies indicated that, student achievement and academic success are complex in nature and related to multiple variables [6]. In a broad sense, all students face some series 
of challenges and stressors. But more likely, the nursing students are the ones who are at the center of experiencing stress [7]. Many factors have been identified to influence academic performance either positively or negatively [8], however, much of the recent research; indicated that academic motivation is an important underlying factor and component in learning. These identified factors which include; socioeconomic background [9, 10, 11], learning environment $[11,12]$, study skills $[13,14]$, sociodemographic variable [15], social factors [16] and past academic achievement [3] exert a degree of influence on academic achievement. The concomitant problems arising from these factors can lead to lack of motivation to study, poor attitude towards learning, lack of concentration, diverted attention and consequently poor performance [9].

This study focuses on identifying the perceived forms in which these factors influence the academic achievement of student nurses.

\subsection{Statement of Problem}

Nursing is one of the courses that attract thousands of students in Nigeria and worldwide. But not all students who enroll and study nursing finish their academic requirement and graduate as polyvalent nurse. One of the reasons of the high attrition rate is academic performance [9].

The escalating dwindling in the academic achievement rate of student nurses in Nigerian universities has undoubtedly become a social phenomenon and nursing educators in particular are becoming rather agitated.

A number of factors affect the academic performance of student nurses and may positively or negatively influence their academic achievement. In view of this, the present study, sought to investigate the perception of student nurses on the variables influencing their academic achievement in Nnamdi Azikiwe University, Nnewi Campus.

\subsection{Objective of the Study}

The main purpose of the study is to determine the perception of student nurses on the variables influencing their academic achievement in Nnamdi Azikiwe University, Nnewi Campus.

Specifically, objectives of this study include:

I. to determine the overall academic performance of nursing science students of Nnamdi Azikiwe University.

II. to determine the form in which socio-demographic factors influence academic achievement of nursing science students

III. to determine the socio-economic variables of parent that influence the academic achievement of nursing science students.

IV. to determine variables in the environment that influence academic achievement of nursing science students.

V. to determine the psychological variables that influence the academic achievement of nursing science students.

VI. to determine the influence of past academic performance on the academic achievement of nursing science students.

VII. to determine the study skills that influence the academic achievement of nursing science students.

\subsection{Research Hypothesis}

Ho: Parental socio-economic status does not significantly affect the academic achievement of the nursing student.

\subsection{Limitations and Delimitations of Study}

The study is limited to students in Nnewi campus of the University, from second year to final year. It is further delimited to the use of questionnaires for data collection and grade point Average (GPA) provided by the student as a measure of academic achievement.

\section{Theoretical Framework}

\section{Maslow's Hierarchy of Needs}

According to Maslow's theory of motivation, needs are the major factors in achieving motivation. He sought to explain it by reference to a 'hierarchy of human needs'. He believed that at any given moment a person's behavior is dominated by those of his needs which have great potency. As their lower physiological needs are adequately satisfied, motives at a higher level in the hierarchy come into play. The hierarchy is illustrated in figure 1 below [17].

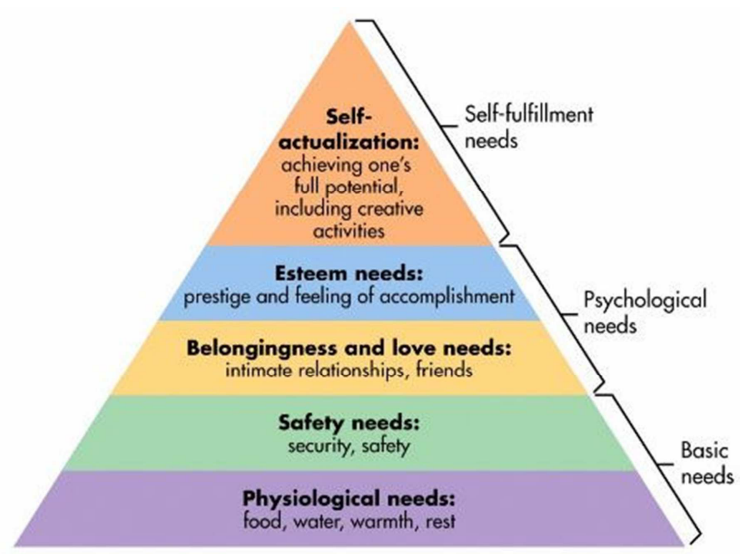

Figure 1. Illustration of Maslow's hierarchy of needs

In educational application, no learning will take place unless the students' basic needs are met. A student nurse who does not feed well, before going to school, lack good shelter or comfortable home, may be seriously affected in the course of learning. Such a learner looks dejected and unorganized, nor a student who is being bullied or sick feels safe to carryout academic activities effectively. Safety needs are protection against bodily harm, danger, deprivation or threat. Both adults and children tend to avoid various forms of perceived danger and unfamiliar situation. The next levels of need (love/belonging, self-esteem, and self-actualization) are 
very important in the life of the student nurse/ learner because of the following benefits:

I. It promotes positive self-concept.

II. It promotes hard work in the course of learning.

III. It provides student's academic performance.

IV.It encourages positive change in the behavior of the student nurse.

V. It contributes to improved teaching and learning process [9].

\section{Methodology}

\subsection{Research Design}

The study adopted a descriptive survey approach to determine the variables influencing academic achievement, among Nursing Science students in Nnamdi Azikiwe University.

\subsection{Sample and Sampling Procedure}

Using Yaro Yamane's formula, the sample size of 108 student nurses were selected using stratified random sampling technique. This was employed to ensure representation of the different levels of study from a target population of 146 .

\subsection{Instrument and Method of Data Collection}

Self-structured questionnaire was used for data collection using the direct service system to ensure prompt return of the questionnaire. Based on the literature review variables of socio-demographic factor, socioeconomic status, psychological, environmental factors and variables related to study skills were used in structuring the questionnaire. Using Spearman Correlation Coefficient to determine the reliability estimate of the instrument based on split half method. The $\mathrm{R}_{\mathrm{w}}$ value of 0.98 was gotten, hence instrument considered reliable for the study. The questionnaire elicited information on personal data, past academic achievement (CGPA), and perceived variables which influence their performance in school. At the end the return rate was $100 \%$.

\subsection{Method of Data Analysis}

The data were analyzed Statistical Package for Social Science (SPSS version 16). Data were presented and described using frequency tables, bar chart, pie chart and simple percentage distribution. The null hypothesis was tested at 0.05 alpha level using Chi square statistical techniques.

\subsection{Ethical Consideration}

Approval was sought and obtained from the ethical committee in Nnamdi Azikiwe University Teaching Hospital. The researchers ensured that all information given by the respondents were treated with utmost confidentiality by maintaining anonymity.

\section{Analysis and Discussion}

\subsection{Socio-demographic Characteristics of Respondents}

Table 1. Showing socio-demographic characteristics.

\begin{tabular}{lll}
\hline Characteristic & Frequency & Percentage \\
\hline 1. Sex & & \\
Male & 15 & 13.9 \\
Female & 93 & 86.1 \\
Total & 108 & 100 \\
2. Age & Frequency & Percentage \\
15-19 & 7 & 6.5 \\
20-24 & 63 & 58.3 \\
25-29 & 23 & 21.3 \\
30-34 & 4 & 3.7 \\
35+ & 11 & 10.2 \\
Total & 108 & 100 \\
3.Marital Status & Frequency & Percentage \\
Single & 86 & 79.6 \\
Married & 22 & 20.4 \\
Divorced & 0 & 0 \\
Separated & 0 & 0 \\
Total & 108 & 100 \\
\hline
\end{tabular}

Data in Table 1 shows that the majority of the respondents $86.1 \%$ (93) were females, while $13.9 \%$ (15) of the respondents were males. Around 58.3\% (63) of the respondents were between the age range of (20-24), while $21.3 \%$ (23) were between (25-29), 10.2\% (11) were (35 and above), $6.5 \%$ (7) were between (15-19) and 3.7\% (4) were (30-34).

Distribution of the marital status as presented in Table 1 shows that greater percentage of the respondents $79.6 \%$ (86) were single while $20.4 \%$ (22) were married.

\subsection{Academic Information of the Respondents}

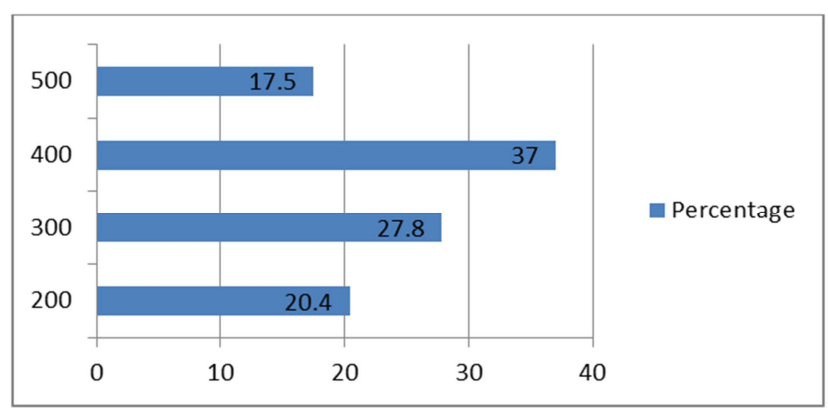

Figure 2. Distribution of Students' Percentage Based on Year of Study.

From Figure 2, the majority of the respondents $34.3 \%$ (37) were in their fourth year of study, $27.8 \%$ (30) were in their third year, $20.4 \%$ (22) were in their second year while $17.5 \%$ (19) were in their fifth year of study.

\subsection{Research Questions}

\subsubsection{Academic Performance}

What is the general academic performance of Nursing Science students in Nnamdi Azikiwe University, Nnewi Campus? 
Table 2. Cumulative Grade Point Average of the respondents.

\begin{tabular}{llll}
\hline CGPA & Freq & Percentage & Remark \\
\hline $1.00-1.49$ & 0 & 0.0 & --- \\
$1.59-2.49$ & 2 & 1.9 & Very poor \\
$2.50-3.49$ & 43 & 39.8 & Poor \\
$3.50-4.49$ & 44 & 40.9 & High \\
$4.50-5.00$ & 6 & 5.6 & Very high \\
Unknown & 13 & 12.0 & ---- \\
Total & 108 & 100 & Average Performance \\
\hline
\end{tabular}

The data in Table 2 Shows that the overall academic performance of the respondents is Poor. Specifically, 5.6\% (6) of the respondent had very high performance with a 4.50 5.00 CGPA, $40.9 \%$ (44) of the respondent had a high performance with a CGPA between 3.50-4.49, while $39.8 \%$ (43) of the respondent had poor performance with a CGPA between $2.50-3.49$ and $1.9 \%$ (2) of the respondent having a very poor performance with CGPA between 1.59-2.49. This shows that about $50 \%$ of the respondents had a poor academic performance.

The forms in which the factors of academic achievement exert their influence on student nurses are presented in line with the research questions.

\subsubsection{Socio-demographic Variables}

What are the socio-demographic variables which influence the academic achievement of Nursing Science students?

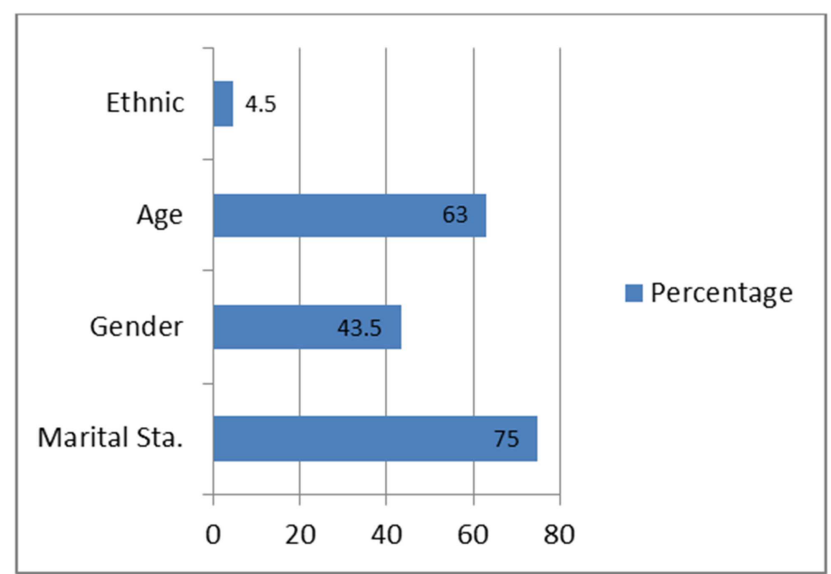

Figure 3. Percentage Distribution of Socio-demographic Characteristic Influencing Academic Achievement.

Figure 3. Shows that socio-demographic characteristic in the form of marital status $74.1 \%$ (80) and age $63 \%$ (68) were perceived by the respondent to influence the academic achievement of nursing science student. Gender which has $43.5 \%$ (47) and ethnic group with $17.8 \%$ (19) had the least influence in that order.

\subsubsection{Socioeconomic Variables}

What are the socioeconomic variables that influence the academic achievement of Nursing Science Students?
Table 3. Percentage distribution of, socioeconomic variables influencing Academic achievement.

\begin{tabular}{lll}
\hline SES Variables & Frequency & Percentage \\
\hline Parental income & 90 & 83.3 \\
Educational level of parent & 72 & 66.7 \\
Family size/structure & 46 & 42.6 \\
Parent's occupation & 57 & 52.7 \\
\hline
\end{tabular}

The data in Table 3 shows that the respondent are influenced by socioeconomic variables in the form of parental income $83.3 \%$ (90), educational level of parent $66.7 \%$ (72), and parent's occupation $52.7 \%$ (57) while family size/structure has least influence on the academic achievement of nursing science student with $47.2 \%$ (51).

\subsubsection{Environmental Variables}

What are the variables in the environment that influence the academic achievement of Nursing Science student?

Table 4. Showing the percentage distribution of environment factors influencing academic achievement.

\begin{tabular}{lll}
\hline Environmental Variables & Frequency & Percentage \\
\hline School location & 73 & 67.6 \\
School structure & 51 & 47.2 \\
School type & 21 & 19.4 \\
School basic amenities & 86 & 79.6 \\
Home environment & 28 & 25.9 \\
\hline
\end{tabular}

The data in the Table 4 shows that only two environmental variables significantly influence the academic achievement of Nursing Science Student. Specifically, school location 67.6\% (73) and school basic amenities 79.6\% (86). The other variables which include school structures $47.2 \%$ (51), home environment $25.9 \%$ (28) and school type $19.4 \%$ (21), were considered to have less significant in their influence on academic achievement in that order.

\subsubsection{Psychological Variables}

What are the psychological variables that influence the academic achievement of Nursing Science students?

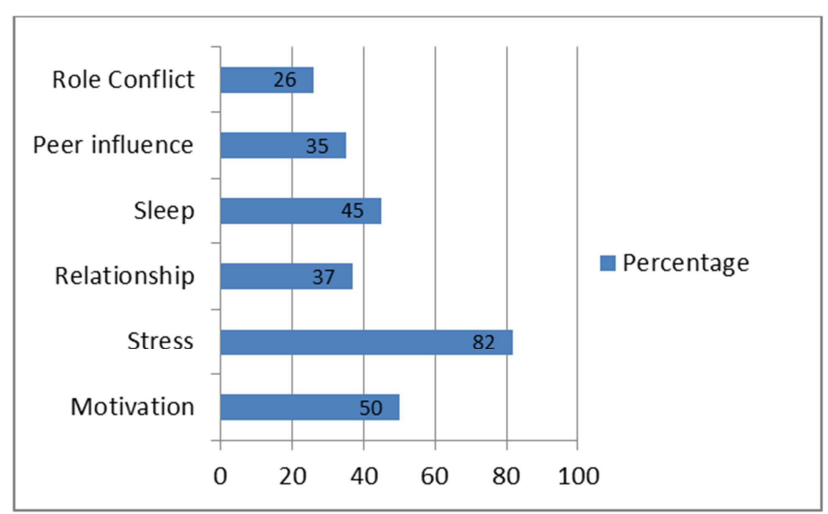

Figures 4. A bar chart showing the percentage distribution of psychological variables that influence academic achievement.

Data presented in figure 4, reveals that two variables, stress 82.4\% (89) and Academic motivation 50\% (54) were identified as psychological variable influencing academic performance. Other variables include; satisfaction of basic 
needs $45.4 \%$ (49), social relationship $37 \%$ (40), peer influence/role model $34.3 \%$ (37) and role conflict $26 \%$ (28).

\subsubsection{Past Academic Achievement}

What is the influence of past academic records on the academic achievement of Nursing Science Student?

Table 5. Percentage distribution of responses on the influence of past academic records on academic achievement.

\begin{tabular}{lll}
\hline Responses & Frequency & Percentage \\
\hline Yes & 72 & 66.7 \\
No & 36 & 33.3 \\
Total & 108 & 100 \\
\hline
\end{tabular}

$66.7 \%(72)$ of the respondents as shown in table 5 believes that past academic records influence present and future academic achievement while $33.3 \%$ (36) of the respondent believes to the contrary.

\subsubsection{Study Skills}

What are the study skills that influence the academic achievement of Nursing Science Students?

Table 6. Percentage distribution of study skill variables that influence academic achievement.

\begin{tabular}{lll}
\hline Study Skills & Frequency & Percentage \\
\hline Learning approach & 73 & 67.6 \\
Attendance to lecturers & 71 & 65.7 \\
Time management & 82 & 75.9 \\
Group discussion & 70 & 64.8 \\
Clinical experience & 63 & 58.3 \\
\hline
\end{tabular}

The data in Table 6 shows that at least $63 \%$ of the respondents believe learning approach, attendance to lectures, time management, discussion groups and clinical/lab experience influence academic performance. With time management $75.9 \%$ (82) being the most significant variable.

\subsubsection{Research Hypothesis}

Ho: parental socioeconomic status does not significantly affect the academic achievement of nursing science student.

Table 7. Hypothetical Responses on Socioeconomic Status of Parent and Academic Performance.

\begin{tabular}{|c|c|c|c|c|c|c|}
\hline $\mathbf{S} / \mathbf{N}$ & STATEMENT & SA & $\mathbf{A}$ & D & SD & $\mathrm{X}^{2} \mathrm{Cal}$ \\
\hline 1 & $\begin{array}{l}\text { Parental income of student nurses influence the level of their academic achievement in terms } \\
\text { of satisfaction of basic need }\end{array}$ & 47 & 48 & 7 & 6 & 71.78 \\
\hline 2. & $\begin{array}{l}\text { Educational level of parents affects the students' performance due to the varying of parental } \\
\text { involvement in their child academics. }\end{array}$ & 23 & 49 & 27 & 9 & \\
\hline 3. & $\begin{array}{l}\text { Student nurses from families with small size/structure perform better due to the level of } \\
\text { parental attention given to their academics. }\end{array}$ & 12 & 34 & 44 & 18 & \\
\hline 4. & $\begin{array}{l}\text { The parent's occupations which affect their status in the society affect the academic } \\
\text { performance of the student nurse. }\end{array}$ & 18 & 33 & 36 & 21 & \\
\hline \multicolumn{7}{|c|}{ Chi-Square Tests } \\
\hline & & \multicolumn{2}{|l|}{ Value } & Df & Critical value & Tabulated \\
\hline \multicolumn{2}{|c|}{ Pearson Chi-Square } & \multicolumn{2}{|l|}{71.78} & 9 & 0.05 & 16.91 \\
\hline \multicolumn{2}{|c|}{ Number of valid cases } & \multicolumn{4}{|l|}{432} & \\
\hline
\end{tabular}

Finding: The result of the analysis in Table 7 showed that the chi square calculated (71.8) is greater than the chi square tabulated (16.91) at 0.05 alpha level. Hence the null hypothesis was rejected and the alternative hypothesis accepted which state that parent's socioeconomic status significantly affects the academic achievement of Nursing Science Student.

\section{Discussion of Major Findings}

\subsection{Academic Performance}

Findings from data analyzed in response to research question 1 which sought to determine the academic performance of student nurses showed that, about $50 \%$ of the respondents had poor academic performance. This level of academic performance can be improved or raised if the variables that influence these students are identified and the positive alternative factors harnessed to enhance their academic achievement.

Based on this finding, the students identified variables perceived as being influential to academic achievement as follows:

\subsection{Socio-Demographic Variables}

The finding of the data analyzed in relation to sociodemographic variables as shown in figure 3, showed that marital status and age are the major socio-demographic variable which influences academic performance supported the work in reference [15]. The poor influence of gender and ethnic group as a socio-demographic variable that influence the academic achievement congruent with the work in [11], [15], but contrary to the findings in [18], a significant gender differences were discovered in favour of the females. Marital status and increasing age comes with strain and responsibilities which could affect academic performance positively or negatively. Student nurses that are single tend to be less distracted by family responsibilities and child care compared to married student nurses. While increase in age can be said to increase understanding of concepts, it can also bring out decline in gasping of concept. A person's gender and ethnic group as perceived by the respondent has no bearing in their academic performance. 


\subsection{Socioeconomic Variables}

Findings from the data analyzed in response to research question 3, as shown in Table 3, reveals that student nurses perceive socioeconomic status in the form of parental income, occupation and educational level of parent to have more significant influence on academic performance compared with Family size/structure. This finding is consistent with the work in [5], [10], [11], in which socioeconomic status had significant influence on academic achievement. However, contrary to the finding in this study, the studies in [5] indicate that family size had significant effect while in [9] educational level of parents had no significant influence on academic performance of student nurses.

In lieu of the above, meeting the basic needs of students, dependent on their parents is essential to academic performance, in line with the Maslow's theory of motivation/needs.

\subsection{Environment Variables}

Table 4 depicted basic amenities and school location as major variables in the environment that affect academic performance. Other variables such as structures, school type and home environment were perceived to be of low significance. This finding supported the work in [11], [12], in which a significant relationship was found between learning environment/location and academic performance, but contrary to the studies in [8], environment had a low significant effect among other factors on academic achievement.

This finding brought to light the need to provide the needed basic amenities, as well as modify the school environment from its location to create a safe and an enabling environment conducive for learning and high academic achievement. As shown from the theoretical framework in Abraham Maslow's hierarchy of needs, students need to feel safe and secure in their environment, because when these basic needs are met, individuals (student nurse) can focus on higher level needs of intellectual achievement in which the urge or motivation to learn increases.

\subsection{Psychological Variables}

Academic motivation and stress were perceived to be the major variables of psychological factor, to exert significant influence on academic achievement, as shown in figure 4 . Other variables include; social relationships, role conflict, peer influencelrole model and sleep. This finding concurred with the finding in [5] and [9] that highly motivated nursing science students are significantly better in their academic performance than their less motivated counterpart.

Nursing science students are at the centre of expressing stress as shown in figure 4 , with $82 \%$. However, while stress can undermine and reduce the efficiency of the student nurse, motivation is also the driving force that can catapult them to high academic achievement. An integrated learning system juxtaposed in a way that will reduce stress is encouraged in the study.

\subsection{Past Academic Records}

Table 5 shows that majority of the respondent $(66.7 \%)$ believes that past academic records evidenced by their previous grade point average has significant influence on academic performance.

Studies as in reference [18] revealed that, achievement motivation and self-concept which could be a product of previous academic records are significantly related to academic achievement. A good and poor academic performance can be a good stimulate to motivate academic achievement.

\subsection{Study Skills}

Findings from the data analyzed in response to research question 7 , which seeks to determine the study skills that influence the academic achievement of Nursing Science Student as shown in table 6; reveal that, time management, learning approaches, attitude towards learning, attendances to lectures, group discussion and clinical experience to be important.

This finding was in agreement with the findings in [12], in which a significant relationship between student learning approach/attitude and their academic achievement was found.

It is important to note, that the identified variables do not act in isolation but interact to exert a certain degree of influence on academic achievement. This interaction may be positive or negative, depending on the degree of academic motivation for high academic performance.

\subsection{Research Hypothesis}

Finding: After the analysis, the test of hypothesis shows that the null hypothesis was rejected and the alternative accepted that, parental socioeconomic status significantly affects the academic achievement student nurses. The result differs from the finding in [9] in which parental socioeconomic status does not significantly influence academic achievement of nursing science students. However, the finding of this study is line with the finding in [8] and [11] in which a significant relationship between socialeconomic status of parent and academic achievement of students was found.

In a more common sense assessment, self-supporting students are likely to miss class due to work, the pressure of putting food on the table and the payment of tuition fees. The fact remains however that classroom attendance is necessary for a better understanding of their knowledge and its application. In some schools class attendance is compulsory and has a bearing on the grades of the students. Given the above mentioned assumptions, the self-supporting student therefore gets lower grades than their classmates who belong to the higher socio-economic status.

Positive parental attitude towards their children such as high interest in their children's academic efforts and their knowledge of the importance of good academic performance can bring about good performance. Students with rich parents have certain needs; physical and psychologically, which when met, contribute positively to their academic performance [11]. These needs, which may include 
conducive reading atmosphere, good food, provision of books and other materials and so on help to promote effective learning and good performance in schools.

Therefore, socioeconomic status and its variables play a considerable role in the academic achievement of nursing science student.

\section{Implication of Study}

The result of this study has far reaching implication for nursing education and the general public. Attrition of student nurses due to poor academic achievement as a consequence of various negating factors, can lead to shortage of man power and inefficient delivery of health care services due. And if student nurses that are incompetent are graduated, it will be tantamount to endangering the life of the client/public and denting the image of the profession.

The professional bodies, stakeholders and policy-makers, administrators and teachers, charged with the responsibility of maintaining/improving the professional standard in both nursing education and practice are to examine and understand the various factors that influence the academic achievement of nursing science student and give each institution, school, group, or student, a unique consideration, especially during accreditation and policy making in areas such as curriculum planning to reduce stress, ensuring availability of learning resources and adequacy of learning environment and so on, leading to a focused and goal oriented interventions/ recommendation.

To the student Nurse, knowledge is power; self-awareness of the variables that influence one's academic performance is first step towards developing an effective coping strategy or exploiting the available resource to enhance ones academic achievement.

The parents are not left out, because in view of the poor economic state of our nation, and considering the high cost of education, poor academic achievement is the least any parent will expect, therefore parents should understand their part and the role the play as an agent of academic achievement motivation irrespective of socioeconomic status.

\section{Conclusion and Recommendation}

They key to improving, maintaining and ensuring a continual delivery of efficient and effective health care system partly depends in the training of competent health care professionals of which the majority are nurses. Therefore, the factors which affect the training of these nurses should be of serious concern to all stakeholders in both the educational and professional bodies. Identification and positively harnessing these factors will create a more enabling environment for student nurses, improve the level of academic performance there by ensuring a better provision of health care.

Based on the finding of this study, the following recommendation has been proffered so as to create an atmosphere conducive for high academic achievement;
I. Balance in curricular and extracurricular activities should be maintained by the students to avoid undue stress.

II. Programs aimed at positively uplifting the student's academic motivation should be organized intermittently and attendance to workshops encouraged.

III. The school through partnership with resource persons, NGOs and government can make available basic amenities and provide solid infrastructures to create an enabling environment.

IV.Work aids and scholarships to deserving students should be encouraged to reduce to reduce the effect of socioeconomic variables.

V. Student's academic performance can be monitored through academic advisers and supervisors who should be in possession of the student nurse's academic records, to foster good learning and study skills as well as encourage group discussions and study groups.

\section{References}

[1] Hogan, P., Moxham, L. and Duyer, T. "Human resource management for the retention of Nurses in acute care setting in hospitals in Australia", Contemporary Nurse: Journal for Australian Nursing Profession. Vol 24(2), April, 2007. Retrieved on $7^{\text {th }}$ July, 2016 from http://www. Questia.com/library/journal.

[2] Merrified, N. "Serious flaws in government approach to NHS staffing", Nursing Times. Retrieved on July $7^{\text {th }}, 2016$ from http://www.nursingtimes.net.

[3] Blackman, I., Hall, M., \& Darmawan, I.G.N. "Undergraduate nurse variables that predict academic achievement and clinical competence in nursing", International Educational Journal. Vol 8 (2), 222-236, 2007. Retrieved June 30, 2016; from http://www.eric.ed.gov/PDFS/EJ834246.

[4] Khaleel, M. "Assessment of the factors affecting academic performance of student nurses: ivythesisnotepad", 2011. Retrieved June 30, 2016 from http://www.researchtopics.blogspots.nl

[5] Muola, J. M. "A study of the relationship between academic achievement motivation and home environment among standard eight pupils". Academic Journal. 2010. Retrieved June 9, 2016, from http://www.academicjounals.org/ERR2/ISSNI1990-3837.

[6] Carrick, J. A. (2010). Student Achievement and NCLEX-RN success: Problems that persist. Nursing Education Perspectives, 32 (2), 78-83.

[7] Ivythesis. (2009). Factors affecting the academic performance of third year nursing students of Laguna college. Ivythesis. Retrieved June 23, 2016, from http://www.ivythesis.typepad.com/term-papertopics $/ 2009 / 09 /$.

[8] Nwatah, V. E. (2011). Six factors that influence academic performance. Article base. Retrieved June 23, 2016, from http://www.articlesbase.com/college-and-universityarticles/six-factors..... 
[9] Ndiok, A. E., Asuquo, E. F., \& Bassey, A. B. (2010). "Motivational variables and academic achievement of nursing science student". West African Journal of Nursing, 21(2), 3338 .

[10] Afolayan, J. A., Bitrus, D., Onasonya, O. Babafemic, A., \& Agama, J. A. "Relationship between anxiety and academic performance of nursing students, Niger Delta University, Bayelsa State, Nigeria. Advances in Applied Research. 2013, vol 4(5):25-33. Retrieved on July $8^{\text {th }}, 2016$ from http://www.pelagiaresearchlibrary.com.

[11] Okoye, N.S. (2009). The effect of gender, socio-economic status and school in Nigerian Integrated Science. Find articles. Retrieved June 23, 2016 from http://www..findariticles.com/p/articles/mi-793673/is-3-29/ain3

[12] Adeyemo, S. A. (2012). The relationship among school environment, Student approaches to learning and their academic Achievement in senior secondary school. International journal of Education 3(1). Retrieved June 30, 2016, http://www.soeagra.comlijert.htm.

[13] Damavandi, A. J., Mahyuddin, R., Elias, H., Daud, S. M., \& Shabani, J. (2011). Academic Achievement of Students with Different learning styles. International journal of Psychological studies. 3(2). Retrieved July 20, 2016; from http://www.ccsenet.org/ijp.
[14] Sunshine, B. A., Lawrence, C. C., and Juan, J. T. "Factors affecting the academic performance of student nurses of BSU”, Internal Journal of Nursing Science. Vol 5(2): 60-65, 2015, doi: 10.5923ij.nursing.20150502.04. Retrieved on July $7^{\text {th }}, 2016$, from http://www. Article.sapub.org

[15] Ebenuwa-okoh, E. E. (2010). Influence of age, financial status, and gender on academic performance among undergraduates. $J$ psychology. 1(2): 99-103. Retrieved on Retrieved July 20, 2016; from http://www.krepublishers.com/00-journals.

[16] Tope, O., (2011). The influence of peer group on adolescents' academic performance: A case study of some selected schools in Ogun state. Ego Booster. Retrieved June 30, 2016, from http://www.omoteretope.com.

[17] Mcleod, S. A. "Maslow's hierarchy of needs". Retrieved on July $7^{\text {th }}, 2016$ from http://www.simplypschology.org/maslow/html

[18] Awan, R. V., Noureen, G., \& Naz, A. “A study of relationship between achievement motivation, self-concept and achievement in English and Mathematics at secondary level". International Education Studies, 4(3) 2012ISSN 1913-9029. Retrieved June 23, 2016, from http://ww.ccsenet.org/ies 